\title{
Tradição e autonomia literária na perspectiva crítica de Ronald de Carvalho
}

\author{
Mirhiane Mendes de Abreu \\ Universidade Estadual de Campinas / Fapesp
}

RESUMO: O ARTIGO OBJETIVA ESTUDAR, A PARTIR DOS ENSAIOS DE RONALD DE CARVALHO, AS REFLEXÕES MODERNISTAS ACERCA DO PROCESSO DE AUTONOMIA DA LITERATURA BRASILEIRA DIANTE DA PORTUGUESA. PARA ISSO, DESTACAM-SE COMO TEMAS RELEVANTES A IMPORTÂNCIA DA CRIITICA LITERÁRIA, O PAPEL DESEMPENHADO PELOS ESCRITORES ROMÂNTICOS E AS DIFERENÇAS LINGÜÍSTICAS EXISTENTES ENTRE UM PAÍS E OUTRO.

ABSTRACT: STARTING WITH RONALD DE CARVALHO'S ESSAYS, THIS ARTICLE INTENDS TO STUDY THE MODERNIST'S REFLECTIONS ABOUT THE PROCESS OF THE BRAZILIAN LITERATURE'S AUTONOMY. IN ORDER TO DO THAT, IT TAKES INTO CONSIDERATION THE CRITICISM LITERARY, THE ROMANTICS' ROLE AND THE DISPARITY LINGUISTICS BETWEEN BRAZIL AND PORTUGAL.

PALAVRAS-CHAVE: RONALD DE CARVALHO - CRÍTICA LITERÁRIA - LITERATURA COMPARADA - ROMANTISMO - MODERNISMO KEY-WORDS: RONALD DE CARVALHO - LITERARY CRITICISM - COMPARATIVE LITERATURE - ROMANTISM - MODERNISM 
ão há literatura sem que a crítica e a poesia se complementem." (Tristão de Athayde)

"Sabe o que estou lendo? O sertanejo de Alencar. Fica-se espantado de relembrar a guerra que fizeram ao homem por causa do tal de dialeto brasileiro." (Manuel Bandeira)

As epígrafes que servem de mote a este ensaio foram extraídas do texto "Romantismo e a Crítica Literária", de Alceu Amoroso Lima (LIMA, 1969: 28), e de uma carta escrita por Manuel Bandeira a Mário de Andrade em 1926 (MORAES, 2001: 270). Os fragmentos destacam questões relevantes para os escritores modernistas, no interior do programa de atualização estética do país: a importância da crítica como condição imprescindível à produção artística; o papel desempenhado pelos românticos, principalmente por José de Alencar, para atingir essa finalidade; e o problema da língua. Nessa linha de raciocínio, este texto pretende destacar a reflexão sobre o período romântico brasileiro realizada por Ronald de Carvalho, procurando compreender como o autor e seus contemporâneos vivenciaram o "instinto de nacionalidade" (ASSIS, 1962: 801) ao lado das relações luso-brasileiras. A preferência pelos seus ensaios decorre de eles conjugarem propostas das vanguardas em ascensão com concepções teóricas herdadas do século XIX, o que contribui para a compreensão da crítica literária modernista, evidenciando as hesitações vividas no período. Outro ponto de interesse advém do fato de o crítico, entregue à causa modernista, ter exercido o papel de aglutinador ao reunir proeminentes personalidades brasileiras e portuguesas, funcionando como um elo entre os dois países. Diante disso, conhecer o pensamento do autor e sua trajetória é ter acesso às múltiplas formas pelas quais a literatura (quer pelas criações, quer pelas críticas) participou do projeto de organização social naqueles anos decisivos do modernismo.

Além de diplomata e conferencista de renome na década de 20 do século passado, Ronald de Carvalho exerceu a atividade de poeta e ensaísta, atuando em inúmeros jornais e revistas do país e do exterior, dentre os quais se destacam O Jornal, Diário de Notícias, Klaxon, Revista do Brasil, Orfeu, Terra de Sol e A Águia. Os textos críticos mais importantes são os livros Estudos brasileiros (a primeira série é de 1924; as demais, de 1931), uma reunião de conferências 
realizadas no México, e a Pequena história da literatura brasileira, obra publicada em 1919 e premiada pela Academia Brasileira de Letras no mesmo ano. Nesses ensaios, o objetivo do autor é claro: avaliar, através de manifestações artísticas, especialmente da literatura, a própria formação da nacionalidade brasileira. Com tal objetivo em vista, a idéia de consciência nacional tornou-se a condição preliminar das suas investigações. O nacionalismo vem sendo, desde o século XIX, o principal mote da crítica literária brasileira. Desse ponto de vista, o "ser nacional" seria a essência da literatura brasileira e, em função desse conceito, o autor procurará situar os traços de autonomia, numa evolução linear e contínua que a diferenciaria da portuguesa. Ao lado disso, são textos que apresentam ao leitor de hoje uma das múltiplas experiências vivenciadas pelos escritores da época, mesmo que não tenham fixado rupturas formais.

Dizendo de outro modo: ele não incrusta na forma poética (como Oswald de Andrade, por exemplo) as inquietações mais prementes da vanguarda; igualmente também não absorve, como Mário de Andrade, uma crítica em cuja forma se identifica, com facilidade, a teoria assumida. O estilo de seus ensaios é convencional. Todavia, eles são norteados pelos novos interesses porque exprimem uma noção muito específica de arte moderna, que supõe a leitura do passado como fomento à criação, daí a necessidade imperiosa de discutirem o fenômeno estético. Diante disso, é na maneira como Ronald de Carvalho pensa a literatura, como percebe a linguagem poética, particularmente no caso do romantismo, que ele adere ao projeto de modernização da cultura brasileira, assumindo na tarefa do crítico o papel que irá impor à do político, preocupado em fornecer estabilidade cultural ao Brasil por meio do novo programa, o qual se propunha também a divulgar, o que fez através de conferências e de colaborações em periódicos internacionais, sobretudo portugueses, em que defendeu as mesmas idéias expostas na sua obra crítica mais conhecida, a Pequena história da literatura brasileira.

No que concerne ao envolvimento com Portugal, além de ter sido diplomata naquele país, colaborou com importantes periódicos literários portugueses (a revista Orfeu talvez figure entre as mais conhecidas), comprometendo-se com o propósito de modernização da literatura em ambos os países. Muitas dessas colaborações em revistas portuguesas são reproduções de seus ensaios anteriormente publicados no Brasil. Tome-se como exemplo a edição de fevereiro de 1924 da revista Terra de Sol, periódico luso-brasileiro, dirigido por 
Tasso da Silveira e Álvaro Pinto. Nela, o artigo intitulado "Literatura Brasileira" é uma síntese das idéias expostas na Pequena história da literatura brasileira e uma reprodução fiel do capítulo "Bases da nacionalidade brasileira", do livro Estudos brasileiros, por sua vez uma compilação de conferências proferidas no México. O mesmo assunto exposto no Brasil e em terras mexicanas e portuguesas sugere que, fosse na qualidade de diplomata, fosse na de historiador e crítico literário, Ronald de Carvalho encarou suas diversas funções como um mesmo programa político e fez do tema da nacionalidade literária a linguagem de expressão desse programa.

Diante desse conceito, o historiador irá sistematizar proposições para a literatura brasileira, considerando desde a influência ibérica até o nascedouro da nacionalidade, presente já nas primeiras manifestações no Brasil, dando mostras e justificando sua autonomia. A questão mais premente para o caso brasileiro é definir a nossa origem, ao lado de outras definições como o "caráter", o "progresso" e as "fases", traçando assim uma metodologia para se constituir a história das letras nacionais. Com esse modelo, Ronald irá dividir o processo de constituição da nacionalidade em três períodos: o de formação (1500-1750), o de transformação (1750-1830) e o autonômico (1830-1925), discutindo, no interior da periodização, a preponderância e o declínio do legado cultural português. No centro dessa questão, impõe-se sublinhar a sua abordagem do romantismo, o "período autonômico", porque, através dele, podem ser percebidas as direções pelas quais o autor envereda: 1) o estudo sobre o "espírito" nacional, encarado em tom épico e, desse modo, fazendo sobreviver o ponto de vista do próprio romantismo; 2) o exame centrado no fato estético, marcando nas análises o debate preponderante das vanguardas e ressaltando como qualidade artística a obra que refletisse maior individualidade poética.

Cabem aqui algumas explicações. Primeiramente, quando se aponta o "tom épico" marcante na crítica de Ronald de Carvalho, o que se deseja expressar, partindo de uma formulação de Roberto Ventura, no livro Estilo tropical, é que a busca pela essência nacional delineou a crítica e a história literária brasileira desde o momento romântico, quando foram erigidas as primeiras formulações a respeito do nosso processo formador, o que foi feito com acento de grandiosidade e heroísmo, a exemplo de uma epopéia (VENTURA, 1991: 162-167). Por outro lado, se a obra de Ronald de Carvalho aceita e adota esses conceitos de matriz oitocentista, tais conceitos também se dirigem pelos 
novos rumos teóricos do século XX, já que suas reflexões são concentradas no fato estético, buscando identificar neste os elementos capazes de fomentar a própria criação literária.

A partir da análise do romantismo são formulados os princípios críticos de Ronald de Carvalho, enfeixados por dois padrões, o reflexivo e o expositivo. O padrão reflexivo trata justamente do que fala Antonio Candido, em "Literatura e Cultura de 1900 a 1945", ou seja, do fato de a dialética do nacionalismo/cosmopolitismo vir delimitando o fluxo da literatura brasileira, o que seria uma espécie de tensão no seu desenrolar histórico (CANDIDO, 1985: 110). Graças a esse padrão, é possível extrair a seguinte idéia: como a literatura espelha o meio circundante, sendo este seu principal condicionante, é preciso transformar o meio a fim de proporcionar às letras pátrias um terreno mais frutífero. Entretanto, apesar de essa modificação ser lenta e carecer de recursos vários, o "intrépido povo", o português (que mais teria influído intelectualmente o brasileiro no processo de caldeamento de raças), teria deixado como legado o heroísmo, daí afirmar continuamente que "a literatura brasileira é o produto do esforço isolado dos escritores" (CARVALHO, 1976: 50). Se existia uma carência, existia, por outro lado, um projeto (ou "esforço") para superá-la e Ronald de Carvalho localiza esse processo de autonomia não pela ingênua imitação das formas estrangeiras, e sim conforme esteja presente o grau de traço pessoal nessa importação, a qual, assimilada, é devolvida em tons nacionais e individuais no processo de criação.

Compreende-se aqui o segundo padrão, o expositivo. Ronald de Carvalho tomava a história literária como parte do processo histórico geral, erigindo os cânones e os ícones da tradição. Nesses termos, há em sua perspectiva, mesmo na exposição panorâmica presente em pequenos ensaios, o primado da observação diacrônica, o que implica um conceito de tempo modelado, não pela cronologia do calendário, mas fundado no ritmo da experiência literária e na memória cultural. O resultado disso não é, como aparenta, uma simples produção erudita de um texto bem escrito. Em virtude justamente do seu sólido e claro padrão expositivo é possível perceber uma narração voltada para questões bem determinadas, e que inscrevem os pressupostos críticos do autor na modernidade. A sua história literária não visa a um cumulativo de obras. A sua história literária, sobretudo quando enfatiza o romantismo e, a seguir, a arte moderna, constituiu-se sob a égide da modernidade à me- 
dida que se afastou do princípio de quantidade inserida na "evolução" da literatura e, em seu lugar, adotou por critério o estilo individual do autor, a sua originalidade e a sua habilidade de incorporar tendências universais, por vezes conflitantes, na obra literária. Por isso, a regra do seu padrão expositivo é introduzir a estética romântica pelas realizações européias e comparar os autores paradigmáticos brasileiros aos principais artistas da cultura ocidental. O segundo balanço visa a observar as influências dos maiores nos menores em seu tempo e o que deles restou na literatura sua contemporânea.

Ao falar de poetas menores, seguidores que foram de cada um dos expoentes analisados, Ronald de Carvalho aborda também questões de método para a história literária e justifica a adoção desse critério. Ciente de que seu texto tinha por destino "vulgarizar, nos seus delineamentos, a fisionomia da nossa literatura" (CARVALHO, 1968: 206), o crítico assume que procurou lançar luzes para as "figuras de maior relevo", pois estas imprimiram nas letras brasileiras um "caráter específico" (CARVALHO, 1968: 245). O problema constitutivo de tais ensaios reside em justificar a existência de uma especificidade literária brasileira, daí que seus esforços se dirigiram em avaliar os escritores que teriam efetivamente contribuído para isso. Abarcando fontes e influências de um poeta sobre o outro, o crítico compartilha, ainda, dos princípios da literatura comparada. O ato crítico adotado é fundamentalmente comparativo, cujo método estaria na base da instituição da particularidade da literatura brasileira, constantemente entrelaçada com relações internacionais como pressuposto das grandes obras daqui. E, ao endossar uma espécie de projeção dos "grandes" sobre os "menores", retoma a questão do estudo comparado como parte intrínseca da formação da história literária.

Com essa problemática em vista, Ronald de Carvalho, mantendo a coerência dos padrões reflexivo e expositivo, dedica-se a discorrer sobre a prosa romântica brasileira. Para isso, oferece uma visão panorâmica dos referentes prefiguradores do gênero no Brasil e credita a Teixeira e Souza e Joaquim Manuel de Macedo (a este com maior ênfase e importância) o papel inaugural de fixadores dos costumes, porque compreenderam "as tendências da nossa alma popular, sentimental e piegas" (CARVALHO, 1968: 248), pressuposto para se compreender o estilo nacional.

O ponto de partida para se abranger o "período autonômico", como já se procurou demonstrar aqui, segue o viés comparativo. Para o estudo da 
prosa romântica será acrescido, de modo especial, o alcance do estilo literário brasileiro, observação que conduz ao estudo mais pormenorizado de José de Alencar, a quem concedeu uma análise menos panorâmica e mais pontual. No exame de Ronald de Carvalho, o escritor cearense seria o de maior relevo em todo o período romântico porque, embora tenha produzido obras que superassem o conteúdo nacional, deu a este conteúdo uma dimensão estilística sem par até o momento:

Aprendemos com ele a ter estilo, isto é, a considerar o romance como uma obra de arte, e não simplesmente como um divertimento, um mero jogo de situações, mais ou menos possíveis, ou um punhado de anedotas picantes. Se não bastassem as suas qualidades de lirista dedicado e sutil, Alencar teria ao menos influído pelo brilho da forma, antes dele descurada, ou melhor, desconhecida em nossa literatura. (CARVALHO, 1968: 252)

A fim de descrever e discutir a formação do estilo literário brasileiro a partir de José de Alencar, Ronald de Carvalho conjuga exposição do tema e do pressuposto crítico-teórico que assume, segundo o qual o alcance da Beleza só seria possível através da poesia. Movimentando-se pelo romance de Alencar, seus conceitos e sua assimiliação das referências importadas, incluindo no debate o exame do local/universal, o estudioso atribui como o eixo da constituição do estilo próprio do romancista (e, portanto, da literatura brasileira) o fato de ele ter assimilado, no interior da prosa, a perspectiva da poesia, construindo frases melódicas de resultado sonoro e elaboradas em sentido figurado, base para a formação da imagem poética. Alencar era "antes de tudo, poeta", sentencia o crítico. Pondo o seu indianismo em confronto com o de Gonçalves Dias, Ronald de Carvalho atribui maior relevância ao prosador, como resultado do exercício consciente em conduzir a autonomia da arte literária via renovação do idioma:

O indianismo de Alencar é superior ao de Gonçalves Dias [...] por ser mais amplo e majestoso. Seus índios não se exprimem como doutores de Coimbra, falam qual a natureza os ensinou, amam, vivem e morrem como as suas plantas e animais inferiores da terra. (CARVALHO, 1968: 250) 
O estilo nacional foi alcançado por Alencar em virtude do livre manuseio da língua, que ele via em toda a sua maleabilidade, tecendo palavras e deixando a imaginação correr para urdir a intriga como "poemas descritivos". Por essa razão, os livros urbanos não deixaram transparecer esse estilo alto como os vistos no indianismo e nos motivos históricos, pois a sua imaginação não se moveria com excelência "sem um laivo de exotismo" (CARVALHO, 1968: 253). Posteriormente, o problema do estilo literário será retomado por Ronald de Carvalho. Em julho de 1924, no periódico América Brasileira, publica o ensaio "Poesia de estilo", em que sublinha como elemento central a expressão, que toca a autobiografia e a história, ou seja, o elemento individual e o coletivo: "O estilo é o que nos exprime. [...] Quem diz estilo, diz autobiografia e diz também história. A vida profunda e misteriosa do espírito transparece na expressão." (CARVALHO, 1924b).

Fundamentando-se no impulso concedido por Alencar ao estilo nacional, Ronald de Carvalho analisa a rede de influências recebidas pelo autor. Preso às fontes importadas, os romances urbanos se restringiriam ao gosto médio do público da época, sem a dimensão universal a seguir alcançada por Machado de Assis. A sua personalidade literária se afirma quando se permite imaginar livremente, o que lhe ofereceu a oportunidade para um uso muito próprio das referências documentais. Apontando o manuseio das referências concretas como influxo à criação, Ronald de Carvalho toca nas deficiências do século XIX; deficiências essas que não seriam partilhadas por José de Alencar em seu indianismo, justamente por ter conseguido ir além da observação e por ter permanecido "brasileiro como poucos", mesmo tendo sofrido "influxo do estrangeiro", os quais teriam sido fundamentais para pensarmos "independentemente de Lisboa ou Coimbra" (CARVALHO, 1968: 259-60).

Para Ronald de Carvalho, a influência de outras literaturas européias foi o passo decisivo para instrumentalizar a nossa literatura, constituindo-se nesse processo uma tradição requintada e fornecendo um alimento essencial como fio condutor de obras futuras. Pode-se inferir como premissa de seu conjunto ensaístico que a influência executa um papel definitivo no processo criador, seja do ponto de vista individual (daí que problematiza a gênese da criação), seja coletivo (tratando, com isso, o estabelecimento da tradição, mormente no tocante ao estilo). A isso importam muito os pressupostos da literatura comparada. Ao eleger a comparação como marca da sua prosa ensaística, Ronald 
de Carvalho remete-se também aos condicionamentos sociais da época. Existem, para ele, dois motores para a criação: o primeiro, estético, deve-se muito à convivência com fontes artísticas diversas, nacionais ou não; o segundo, social, considera o meio cultural, a presença ou ausência de estabilidade e organização social para o estabelecimento da literatura. No bojo desse problema, justifica o impacto do estilo de Alencar sobre os demais escritores, como teria ocorrido com Euclides da Cunha (CARVALHO, 1968: 260).

A condição de um escritor autônomo e, portanto, paradigmático, para o contexto romântico brasileiro, era a capacidade de operar com a tradição literária, estabelecendo para si as regras, os modelos e os critérios seletivos e valorativos a fim de atuar sobre eles. A maior originalidade só seria percebida no escritor que encaixasse na criação a autocrítica e a auto-referencialidade, entrelaçando consciência artesanal com poesia; esta, por sua vez, compreendida em sentido amplo, pois, como se viu, esse princípio se estende à prosa indianista de José de Alencar, que soube garantir originalidade e estilo próprio aos seus romances, justamente por ter sido capaz de manipular consciência crítica e teórica na criação.

Esse engajamento de Ronald de Carvalho ao analisar o passado, tendo por alicerce preceitos da época, pode ser acompanhado pela observação da passagem que teve entre os portugueses, período em que divulgou a especificidade da nossa literatura. Da sua perspectiva, para a devida compreensão dessa identidade, é fundamental o conhecimento dos processos de sistematização da nossa literatura e as formulações essenciais da arte moderna: "De todas as artes, porém, é a da palavra aquela que exerce uma influência mais penetrante, um papel mais saliente na formação das nacionalidades. Um povo sem literatura seria, certamente, um povo mudo, sem tradições e sem passado, fadado a desaparecer como reles planta rasteira nascida para ser pisada." (CARVALHO, 1924a). É o que afirma nos textos transcritos em Terra de Sol e também reproduzidos no periódico América Brasileira, em 1922, por ocasião do centenário da independência e da Semana de Arte Moderna. Seduzido pelos grandes feitos da tradição artística, Ronald de Carvalho vai assim reforçando as razões estéticas de sua perspectiva literária, a qual convivia com o seu projeto de renovação e sedimentação da cultura, para o que se dedicou, inclusive do ponto de vista diplomático. Seu empenho, ao enviar uma colaboração para uma revista portuguesa, permite perceber um programa de cordialidade polí- 
tica e cultural entre os dois povos. A sua premissa se completa no conceito de arte e de tradição publicado em outro periódico lusitano, A Águia:

Nós vivemos nos outros; somos o gesto isolado d'alguém que esteve ou está em nós.

E vamos pela vida fora, inconscientes nativos do que supomos ser, a pensar mal d'outros tipos que somos nós mesmos sob uma máscara diversa...

Todo gesto original é um velho gesto que renasce... (CARVALHO, 1910)

Esse fragmento extraído do ensaio "Do amor, da beleza e da vida", publicado na revista portuguesa A Águia, em 1910, considera o passado como paradigma para a gênese criadora. O texto, adotando uma linguagem figurada, bem distinta dos ensaios da Pequena história, relaciona os contatos entre autores e obras de literaturas de diferentes nacionalidades, o que abrange o móvel da criação e, em seu âmbito, o papel desempenhado pela tradição. Uma breve excursão pelos seus ensaios já deixa perceptível que o conhecimento do passado tem por finalidade captar o intemporal na literatura, o que contribui com o curso da história literária. Essa idéia tem também por finalidade livrar a tradição da idéia de fardo que tornasse futuras criações um simples mimetismo. Desse modo, como exemplificaria a obra de José de Alencar, o nacionalismo na literatura e, portanto, sua autonomia, é o resultado da relação própria e criativa com nomes e obras consagradas. Nisso reside um princípio de nacionalismo que se queria universalizante. Tal princípio nacionalista só produziria obras para todos os tempos se os autores não se reduzissem a tal preocupação, mas se explorassem e transformassem as referências importadas, conferindo-lhes outros sabores, o que significa romper com a linguagem convencional e criar novos códigos, além de imbuir o processo criativo de auto-reflexão no interior da própria obra. Elucidando os valores estéticos dos autores estudados, ainda que numa exposição panorâmica, o crítico carioca procura estabelecer os meios pelos quais a literatura brasileira se constituiria numa tradição distinta e autônoma da portuguesa.

Tal idéia está consignada no ensaio "O irreal na arte", publicado na segunda série do mesmo periódico em 1915, em que diz, a propósito de Correia Dias, que a "arte é um fenômeno do temperamento de cada um, nasce da estesia educada pela visão das cousas interiores, do que está no sub-consciente, do 
que não existe simplesmente, mas em conjunto com a nossa sensibilidade" (CARVALHO, 1915). Essa formulação, elaborada no contexto de um comentário sobre o fato de o artista que analisa não pertencer a nenhuma escola, sintetiza seu conceito de tradição e a relação que o processo criador estabelece com ela. O eixo dessa relação dinâmica reside no fato de que, para Ronald, o verdadeiro artista cria "sem mestres, sem cursos, com uma educação intuitiva", o que ele percebia em Correia Dias, pois, com seu talhe seguro, seria portador de "coloridos milagrosos nos seus noturnos, doçuras de expressão como nas melhores páginas de Dulac ou Barbier, é um sonâmbulo de beleza" (CARVALHO, 1915)

O mesmo se lê na apresentação de Antônio Ferro, quando da estada do modernista português no Brasil. Ao longo do discurso, acrescenta ao preceito da liberdade o do conhecimento do passado, ou seja, da tradição: "O problema da liberdade criadora envolve uma questão básica: a da tradição. Devemos, antes do mais, apurar até onde vai, na obra de arte, a influência do passado, o que representa esse valor no esforço da criação" (CARVALHO, 1923: 34). A partir disso, o crítico fará aproximações entre Ferro e os românticos, diferenciando tradição de tradicionalismo. Atribui ao primeiro conceito a faculdade de ser "um instrumento auxiliar no espírito, um ponto de referência de que este se serve para verificar as novas experiências"; já sobre o segundo, reputa às obras daqueles que, "não tendo energias para realizar obra própria, lastram à feição de parasitas sobre a alheia. Tradicionalismo, em arte, quer dizer mimetismo frio, impassível, monstruoso" (CARVALHO, 1923: 35).

Quando Ronald de Carvalho analisa o romantismo brasileiro, assume um raciocínio que veicula o processo percorrido para a conquista da autonomia da literatura brasileira diante da portuguesa. A proposta teórica que se pode perceber em sua prosa ensaística é, de um lado, marca própria, fruto da educação sólida e cosmopolita que recebera. De outro lado, podem ser consideradas as relações entre tais pressupostos com os abraçados pelos demais modernistas, seja do ponto de vista formal (como se pode perceber pela escrita da história literária de Manuel Bandeira, guardadas, evidentemente, as peculiaridades de cada um), seja no plano das idéias (como se pode identificar em Mário e Oswald de Andrade). Da perspectiva do crítico carioca, a existência de grandes talentos esparsos ao longo do tempo não bastava para estabelecer uma literatura organizada, era preciso ainda criar canais institucionais que garantissem o 
estabelecimento de uma tradição enraizada e duradoura. É, então, no sentido da institucionalização da cultura brasileira que Ronald dirige seus esforços, escrevendo ensaios de divulgação, fazendo conferências e, sobretudo, produzindo uma história da literatura brasileira. Esta, por sua vez, se contribui para a difusão da tradição literária, sintetizando referências teóricas de sua época, é fortemente demarcada por um formato institucionalizado, acadêmico, que a afasta dos modernistas mais radicais. Se o projeto formal o distancia de alguns críticos, existem mais traços contíguos entre eles do que a aparência possa sugerir. Desde a concepção de um projeto para a literatura, preocupada com a sua institucionalização, incluindo nesse contexto o problema das influências estrangeiras, até a assimilação do passado no presente, Ronald de Carvalho apresenta reflexões muito calcadas nas diretrizes do seu tempo.

$\mathrm{E}$ isso se pode perceber se traçarmos um paralelo, ainda que brevemente, entre suas idéias e as de Mário de Andrade. Para ambos, mas cada um a seu modo, a preocupação com a nacionalidade esteve entremeada com o ideal de atualização técnico-estética no Brasil. Ao fazer um "balanço final” do modernismo, Mário de Andrade insiste na idéia de que as produções artística e ensaística da sua época foram estimuladas pela imposição da novidade e pelo "culto à tradição" ("dentro do maior espírito moderno", ressalta o autor) (ANDRADE, 2002: 266). Sob esse último aspecto, o culto à tradição implicava a fusão de três princípios fundamentais: o direito à pesquisa estética, a atualização da inteligência artística e a estabilização de uma consciência criadora nacional (ANDRADE, 2002: 266). Vê-se, assim, que, da perspectiva marioandradina, o que se impunha como fomento à atualização e, portanto, como autonomia definitiva era o conhecimento orgânico e consciente das singularidades brasileiras. Nisso se tornava indispensável conhecer o papel do romantismo, sobretudo o de José de Alencar em seu empenho para constituir um estilo para a literatura brasileira.

No que se refere a esse estilo, merece destaque a análise histórica que faz a respeito da problemática da língua. Interessado em identificar a nossa "expressão verbal" (ANDRADE, 2002: 268), Mário de Andrade dedica uma parte do seu estudo a caracterizar os escritores a partir desse critério. Machado de Assis, desse modo, teria adotado um estilo "luso pelo ideal", embora distinto de um Garret ou Ortigão. Os românticos, por outro lado, teriam compreendido e explorado as possibilidades oferecidas pelo que denomina de "identi- 
dade brasileira”, chegando “a um 'esquecimento' da gramática portuguesa e sua expressão verbal" (ANDRADE, 2002: 268). A coerência para o alcance de um estilo é vista em Alencar, que teria legitimado a literatura brasileira pela "integridade nacional" com que encarou o profissionalismo da sua escrita.

Para Mário de Andrade, o abrasileiramento do português era, antes de mais nada, corolário do seu próprio programa de caracterização da identidade nacional: "O espírito modernista reconheceu que si vivíamos já de nossa realidade brasileira, carecia reverificar nosso instrumento de trabalho para que nos expressássemos com identidade" (ANDRADE, 2002: 235). Na excursão que faz ao período romântico, porém, o crítico paulista não se ocupa de maneira estrita com o nacionalismo, mas com conceitos e teorias que fomentaram a criação dos escritores do período, concedendo-lhes um estilo próprio a partir da ênfase nos processos criativos da obra de arte. Também em torno desse mecanismo, Mário de Andrade procura inserir os românticos (e muito especialmente a problemática estilística enfrentada por Alencar) num contexto mais amplo, constituindo uma tradição na cultura do seu país. Trata-se de uma asserção que traduz, implicitamente, as preocupações do autor com os rumos da literatura brasileira sua contemporânea. O que revela, em essência, é o entusiasmo da busca, a obsessão em acertar e em ser "atual", perseguida por intermédio da pesquisa que levaria o brasileiro a encontrar-se consigo mesmo.

É no mínimo interessante que as qualidades admiráveis de José de Alencar para os modernistas tenham sido o principal pomo de discórdia entre ele a crítica oitocentista. Para exemplificar, basta lembrarmos que, em 1868, Pinheiro Chagas escreveu o artigo "Literatura Brasileira/José de Alencar", expondo as por ele consideradas fragilidades lingüísticas de Iracema (ALENCAR, 1965: 194-200). Em resposta, o romancista incluiu na segunda edição do mesmo livro (1870) um "Pós-Escrito", o que gerou dois estudos de Antônio Henriques Leal, "A literatura brasileira contemporânea" e "Questão Filológica", ambos publicados em 1870 (ALENCAR, 1965: 208-210). Ao propor como distinção de autonomia literária a identidade estilística, Alencar intensificou os preceitos condutores do seu programa de nacionalização literária. A escolha e a valorização dessa bandeira pela crítica modernista evidenciam como pensavam o manuseio da tradição e da pesquisa estética no propósito de atualizar a literatura brasileira, fazendo-a divergir da portuguesa. Essa divergência, contudo, não significava repulsa, mas um desejo de produzir sentido nacional 
ao novo. E o papel da crítica seria justamente o de captar esse sentido e tornálo visível aos seus concidadãos.

$\mathrm{Na}$ reflexão teórica que desenvolveram sobre a história literária, Ronald de Carvalho e Mário de Andrade sintetizam propostas dos anos 20, quando a crítica literária foi encarada como um caminho para se compreender a criação, ao mesmo tempo em que implicava uma visada pragmática do conjunto cultural do país. O modo pelo qual ambos pautaram seus respectivos projetos críticos, procurando nos autores estudados (sobretudo em José de Alencar) uma consciência criadora, mostra que, para eles, tradição não é um fardo, mas implica na conquista de um estilo individual e coletivo, porque diz respeito à autonomia e, logo, à nacionalidade da literatura. Isto os impulsionou à pesquisa de postulados críticos e teóricos da época, fosse para divulgá-los sinteticamente, propagando, por seu intermédio, a "psique brasileira" (como é o caso do primeiro); fosse, como em Mário de Andrade, para fixar-se em tais postulados, absorvendo-os em suas estratégicas argumentativas. Tais postulados, é preciso ressaltar, têm em comum a busca pela identidade nacional.

Ronald de Carvalho, como Mário de Andrade, abraçou contundentemente a causa modernista. Se, do ponto de vista formal, incorporou o discurso acadêmico, sem o tom provocativo dos escritores mais simbólicos do movimento, essa configuração do seu estilo era proposital, consciente e em conformidade com seus propósitos transformadores da nova arte e da conjuntura cultural como um todo. A contribuição de Mário de Andrade para se compreender os pressupostos da crítica de Ronald de Carvalho advém da observação, não de uma paridade entre as conclusões a que chegam os ensaístas, mas da proximidade entre os principais fundamentos teóricos que alimentaram seus estudos e do interesse recíproco em fazer do conhecimento da tradição o caminho para se alcançar um estilo literário próprio. A realização efetiva dos trabalhos dos dois autores orientou a história literária a partir de uma contextualização internacional e nacional. Essa contextualização teve como perspectiva os modelos literários que ofereceram vigor às novas produções, fundamentando com isso a grande questão da identidade nacional. Pela pesquisa sistemática desse tema, os críticos se uniam pelo projeto ambicioso de atualizar esteticamente o país, dedicando-se a estabelecer uma estrutura oficial, a "estabelecer vínculos fortes e duradouros" para a produção e veiculação da cultura (CARVALHO, 1968: 368). 
Em seus ensaios, o crítico carioca demonstrou que o processo da autonomia e da modernização literária passava forçosamente pela relação com as referências diversas, o que significava também constituir uma tradição, considerando nesse âmbito os modelos e modos culturais luso-brasileiros, aproximação a que se dedicou quer como diplomata, quer nas suas mais diversas tarefas intelectuais. Para isso, exalta justamente a individualidade estética, um valor introduzido pelos românticos, a fim de discernir o estilo próprio e autônomo da literatura brasileira, o que foi explorado por ele na proposta de uma crítica que pretendia ser inovadora, pois procurava ir mais adiante no problema nacional, vendo-o para além da temática e refletindo acerca do impulso que essa inquietação forneceu para a consciência criadora e para o fortalecimento da tradição.

\section{Referências Bibliográficas}

ALENCAR, José. Iracema. Edição do Centenário. Rio de Janeiro: José Olympio, 1965.

ANDRADE, Mário de. O empalhador de passarinho. Belo Horizonte: Itatiaia, 2002.

ASSIS, Machado de. Notícia da atual literatura brasileira - instinto de nacionalidade. In: - Obras completas. Rio de Janeiro: Aguilar, 1962.

CARVAlHO, Ronald de. A Águia - Órgão da Renascença Portuguesa, v. VIII - $2^{\mathrm{a}}$ série (jan. a jul. 1910).

. Prefácio. In: A idade do jazz-band. São Paulo: Monteiro Lobato, 1923.

. Terra de sol. Revista de Arte e pensamento. Dir. Tasso da Silveira e Álvaro

Pinto. Rio de Janeiro: Anuário do Brasil, 1924a.

Poesia de estilo. In: América Brasileira. Diretor Elísio de Carvalho. Rio de

Janeiro, julho, 1924b.

. Pequena história da literatura brasileira. Rio de Janeiro: F. Briguiet, 1968.

. Estudos brasileiros. Rio de Janeiro: Nova Aguilar; Brasília: INL, 1976.

LIMA, Alceu Amoroso. O Romantismo e a Crítica Literária. In: . Meio século de presença literária. Rio de Janeiro: José Olympio, 1969.

MORAES, Marcos Antônio (Org.). Correspondência Mário de Andrade \& Manuel Bandeira. 2. ed. São Paulo: Edusp, 2001.

VENTURA, Roberto. Estilo tropical: história cultural e polêmicas literárias no Brasil. São Paulo: Companhia das Letras, 1991. 